\title{
Análisis social de la novela La espina de Alejandro Carrión Aguirre
}

\section{Social Analysis of La Esquina (The Corner) Novel by Alejandro Carrión Aguirre}

\section{Resumen}

El objetivo de este artículo fue analizar los principales problemas en la novela La Espina del escritor ecuatoriano Alejandro Carrión Aguirre. Se ha utilizado una metodología cualitativa, la cual ha permitido analizar una serie de textos afines al tema que nos ocupa. Los resultados indican que, los personajes de la novela mencionada, reflejan varios problemas en contra de su seguridad y vida. Finalmente, concluimos que la literatura es el medio más eficaz e idóneo para denunciar hechos lacerantes que se presentan en la sociedad, de manera especial, en los personajes de la novela La Espina.

Palabras clave: Maltrato; violencia; La espina; Alejandro Carrión.

\section{Abstract}

The objective of this article was to analyze the main problems in La Espina Novel by the Ecuadorian writer Alejandro Carrión Aguirre. A qualitative methodology has been used, which has allowed it to analyze a series of texts related to the subject at hand. The results indicate that the characters in the aforementioned novel reflect various problems against their safety and life. Finally, it is concluded that literature is the most effective and ideal means to denounce lacerating events that occur in society, especially in the characters of La Espina Novel.

Keywords: abuse, violence, La Espina, Alejandro Carrión.

1 Máster en Literatura Española por Universidad de Barcelona. Docente investigador de la Sección Lenguas Hispánicas y Literarias de la Universidad Técnica Particular de Loja, Ecuador. Correo: cgsarango@utpl.edu.ec Orcid: https://orcid.org/oooo-0003-1303-7702

2 Licenciado en Ciencias de la Educación Mención Lengua y Literatura por Universidad Técnica Particular de Loja, Ecuador. Orcid: https://orcid.org/oooo-0oo2-6618-2682

Recibido: 08/01/2021 - Aprobado: 05/02/2021 


\section{Introducción}

En antesala al estudio, conviene mencionar a Mario Vargas Llosa en su ensayo: La verdad de las mentiras (1990).

la literatura es el medio más eficaz e idóneo para concienciar a la población, a través de las palabras, ya que solo ella dispone de las técnicas para destilar ese delicado elíxir de la vida: la verdad escondida en el corazón de las mentiras humanas.

Se referencia esta cita porque el novelista pretende justamente mostrar la inconformidad de la realidad humana que es el caso de la novela en estudio: La espina.

El protagonista de esta novela es Darío Nicolás Saralear, quien, a manera de confesión con Dios, escribe su historia relatando todas las desgracias y vicisitudes que le ha tocado sufrir durante toda su existencia. Una infancia infeliz compartida con personas lúgubres que lo han pulido con el fuego de la tristeza y la soledad.

Desde su infancia, su vida es marcada por la tristeza. Su desgracia y arrepentimiento empieza al nacer, al quedar huérfano cuando su madre lo parió. Su padre al sentir el vacío de la muerte de su amada, lo culpa por este acontecimiento y a manera de un falso amor piadoso, lo entrega al cuidado de su tía Rigoberta Montesdeoca. Una mujer perversa y malvada a la que no le importa propinarle castigos sin piedad para hacerle atravesar múltiples vejaciones, y efectivamente, una de las primeras humillaciones que sufre Darío Nicolás Saralear es cuando realizó la primera comunión con botas de mujer que su tía tacaña le compró.

En consecuencia, según el protagonista de la novela, la personalidad de las personas, sus defectos y virtudes dependen de la herencia familiar, en otras palabras, la sangre y los genes determinan la personalidad y la vida de su casta infeliz. Para defender esto, cuenta la historia de su abuelo Salverio, un bandido que comete un homicidio que lo lleva a la cárcel. En ese momento, su hija Julia Enriqueta viaja a la ciudad de Loja para luchar por la libertad de su padre cuando cae en desgracia al asesinar a su compadre.

Cuando estuvo en la ciudad de Loja, Julia Enriqueta conoce al abogado Darío Nicolás. Este personaje es un abogado lleno de vicios debidos a una codicia desmedida. Al conocer a Julia Enriqueta, la conquista y se acuesta con ella al tercer día de conocerla. Julia Enriqueta y el abogado Saralear llegaron a ser amantes y se volvieron cónyuges. Libres de la responsabilidad con el padre de Julia, muerto a causa de su vida delictiva, la mujer tiene un cambio rotundo en su vida, seguramente contaminada con la personalidad pestilente del abogado. De una mujer humilde y sencilla, se convierte en una mujer astuta y hábil que cautiva a cualquier hombre que la conoce. 
Julia Enriqueta se pierde en la soledad y en el abismo de la pasión desenfrenada. No le importó la enfermedad de su esposo que lo llevó a la muerte. Comete traición, infidelidad y adulterio mientras su esposo agonizaba en el sillón. Convivió con uno de sus amantes, un hombre llamado Ricaurte del que queda embarazada de su tercer hijo. No tiene ningún cargo de consciencia al inscribir a su nuevo hijo, Darío Nicolás, con el apellido del abogado Saralear, a pesar de conocer que no es su hijo legítimo. Prefiere evitar la vergüenza y los comentarios de aquellos que juzgarán sus actos de infidelidad.

Desde el día que nació, Darío Nicolás recibió mucho odio de su progenitor ya que lo culpaba por la muerte de Julia Enriqueta. Esto llena de odio a Ricaurte a quien no le importa la suerte de su hijo y lo entrega al cuidado de Rigoberta Montesdeoca, mujer terrible y maniática que criará con mano dura a Darío y a sus otros hermanos. Esto deriva en que, Darío Nicolás al no sentir el cariño de sus padres o familiares comienza a crecer como una persona solitaria agobiada por el dolor y la desesperación. No sentía cariño por sus hermanos ya que los juzgaba por sus actos salvajes, como el homicidio de un niño y la violación indescriptible de una anciana que les lavaba y planchaba la ropa.

A modo de ejemplo, del maltrato y violencia intrafamiliar que sufre el protagonista, el mismo narra cuando es nuevamente víctima de Zoilo y de Servio, sus dos hermanos, quienes, al encontrarse borrachos, lo ridiculizan por no acostarse con prostitutas. Lo llevan a la fuerza a un antro en el que se burlan diciéndole virgo y lo obligan a irse con una prostituta que lo encierra en un cuarto y pretende acostarlo en una cama donde los hijos de ella dormían. Este acontecimiento lo inundó de más odio a la pobreza, a la suerte maldita de hombres y mujeres que se revuelcan en sus actos inmundos y no logran salir de ellos.

En su confesión de vida ha narrado porque su corazón y su espíritu está lleno de espinas que le han clavado las personas con las que ha crecido. No puede olvidar esto y no puede recuperarse para poder dar amor a su hijo y se culpa por la muerte de su esposa que como su madre murió al dar a luz a su descendiente.

En ese orden, una vez presentado un pequeño argumento de la novela, es importante mencionar que la inestabilidad política en la cual se encontraba el país entre 1920-1940, generó una serie de dificultades económicas; esto generó que se produjeran una serie de gobiernos, dictaduras, revoluciones y, sobre todo, múltiples tentativas de guerra con el Perú. De hecho, Sarango (2020, p. 94) asevera que "durante la década de 1930 se forja un movimiento cultural ecuatoriano conformado por escritores, poetas, artistas, pintores, intelectuales de avanzada que refleja la cruda realidad de la sociedad ecuatoriana". Y, justamente, una de esas realidades es el maltrato y violencia que se acometían en el seno familiar de las familias ecuatorianas. 


\section{CIENCIAS SOCIALES}

Otro de los factores que debemos mencionar es el boom bananero que experimento el Ecuador en el gobierno de Galo Plaza Lasso, a finales de la década de 1940, lo cual trajo muchos beneficios (proceso de urbanización), pero profundas desigualdades económicas. En consecuencia, a partir de 1960, es importante mencionar que la Junta Militar de Gobierno expidió la ley a la Reforma Agraria. En esta reforma se puso énfasis en el aspecto social y no en el ámbito económico, lo que generó una mejora en la condición de vida de ciertos sectores sociales. Esto evidenció una praxis socialista en Alejandro Carrión Aguirre, quien en 1959 escribió su única novela La espina, la cual describe una realidad lacerante en el contexto social ecuatoriano: el maltrato y violencia intrafamiliar.

\section{Desarrollo}

En la novela, La Espina, es amplio el número de problemas sociales que se encuentran como el maltrato infantil, el maltrato físico, el maltrato psicológico, la infidelidad, el alcoholismo, la prostitución, la corrupción, el suicidio, el abuso sexual, el homicidio, el parricidio. En efecto, todos estos problemas amenazan el desarrollo de sus protagonistas.

Los problemas sociales atentan contra la paz, la felicidad y la armonía de las personas en su entorno de vida. Una de los objetivos más importantes del ser humano es alcanzar la felicidad y, dejar de lado la soledad. Vivir a plenitud, hacer lo que las personas desean fervientemente sin hacer daño a los demás y practicar los valores que enaltecen a la persona. La siguiente cita explica el significado de la felicidad según el autor de la novela.

La felicidad no viene de la riqueza, ni de la plegaria, ni de la ciencia. La tranquilidad del ánimo no viene de huir de la acción. La inmovilidad no da la calma. La felicidad viene solamente de vivir en plenitud, como vive la flor, como vive la humilde bestia; aceptando la vida sin reticencia y sin huida, saboreándola a pleno labio, sin que la luz de la razón, que nos pone sobre la flor o sobre la bestia, entre a discutirla y nos lleve a abominar de su esencia, a negarla, a hacerle trampas vivas, a sentir vascas ante su infinita delicia, a percibir como impura la infinita pureza. La luz de la razón debe dignificar lo que la flor o la humilde bestia de Dios saben aceptar y vivir; de lo contrario, no es luz, sino tiniebla, que nos equivoca el paso y nos lleva a la sombra del pozo hondísimo, al odio a todo lo que es sano y alegre y acompañado, a la envidia a todo lo que es vida y vigor y aceptación consciente de las maravillas de la fisiología. ¡Todo lo que resista a la vida no es sino suicidio lento y miserable, y cobardía, soledad, incomunicación, abandono! (Carrión-Aguirre, s.f., p. 211).

El maltrato infantil en la novela La espina se encuentra presente en la infancia de Darío Nicolás Saralear, personaje protagonista de esta historia, cuando relata la 
forma en que la mujer que lo cuidaba (Rigoberta) lo castigaba en forma verbal y física cuando se orinaba mientras dormía.

Viendo que los insultos y la correa no servían de nada, - “Tal vez no lo haga de malo, tal vez sea enfermedad", dijo un día en el cual una remota ráfaga piadosa penetró por milagro hasta su alma reseca, su alma de pescado salado-, resolvió curarme. Largo rato estuvo refregándome nalgas, sexo y abdomen con grasas extrañas: sebo de chivo padre, manteca de culebra, enjundia de gallina negra. Esas porquerías me acompañaban hasta el momento en que se abrían las llaves y el manto cálido, más tarde trasmutado en hielo, me cubría. Por la mañana, sobre la grasa hedionda y la piel mordida por la orina, caía la correa (Carrión-Aguirre, s.f., p. 31).

Otro momento en el cual Darío Nicolás Saralear sufre maltrato, ocurre cuando esta mujer lo obliga a que haga su primera comunión con botas de mujer. Esto hace que sea víctima de insultos y burlas de otros chicos que ridiculizaban su apariencia diciéndole botas de marica.

Por la calle, mientras yo casi no podía caminar, porque las botas me aprisionaban fieramente y la vergüenza me cegaba, empujado por su crueldad, vi a mis compañeros. Iban todos felices, hermosos zapatos negros les cubrían los pies, lindas medias emergían de esos zapatos y subían hasta las rodillas, hermosos pantalones seguían luego. ¡Eran limpios, elegantes, sencillos, daba gusto verlos! Mis ojos, tenazmente bajos, solamente miraban zapatos lustrados, zapatos, zapatos de muchacho, zapatos confeccionados para que los usaran los niños, no instrumentos grotescos, prendas de burla, botinas viejas de niña, como las que me habían sido impuestas, para ensuciar el día de mi primera comunión (Carrión-Aguirre, s.f., p. 28).

El maltrato físico dentro de la novela La espina se ejemplifica en la manera en que Ricaurte es agredido por los hermanos de Darío Nicolás Saralear, Servio y Zoilo. La siguiente cita relata como Ricaurte es agredido físicamente y es expulsado de la casa en que vivía luego de que Servio y Zoilo violan a una anciana.

Ricaurte, congestionado por el esfuerzo, un esfuerzo mayor de cuantos, a esa altura de su alcoholismo y disipación, podía realizar, cayó sobre Zoilo como un peso muerto, y no pudo levantarse; y el mozo maldito, sin sorprenderse, sin perder un instante, comenzó a golpearlo con brutales y acerados puños, en pleno rostro, mientras Servio, ágil como un rayo, se ponía los zapatos, y lo relevaba, comenzando a sacarlo de la pieza a puntapiés [...] El instinto que lleva, aun a los zombíes, a tratar de salvarse, de conservar aún la sombra de vida que les queda, hizo que, ciego de terror, Ricaurte tratara de ponerse en pie, mientras sus terribles pupilos lo arrastraban a la escalera y 


\section{CIENCIAS SOCIALES}

lo echaban a rodar por ella, pateándolo inmisericordiosamente [...] (Carrión-Aguirre, s.f., p. 155).

En la novela La espina el maltrato psicológico se da por medio de humillaciones, gritos, amenazas y un amedrentamiento constante de Rigoberta en contra de Darío Nicolás Saralear. El siguiente ejemplo evidencia ello:

Nada hay tan desvalido como un niño empapado en orinas, carcomido por la vergüenza, por el frío, por el olor pungente. Nada hay que esté más cerca de la ruina completa, del ansia de morir, de la sed de irse para siempre. Como es natural, yo me empapaba todas las noches. Sentía, de pronto, que un manto cálido me envolvía, me transita, se apoderaba de mi triste ser. Era que se habían abierto las llaves y que la orina corría libremente. Me quedaba inmóvil, mientras el manto cálido se transformaba en hielo, en un hielo mordiente, que me atenazaba hasta el alba. Entonces, comenzaba el martirio. La vieja se acariciaba la verruga y entraba al día diciendo: "Ya se ha de haber miado este cochino". Ése era mis buenos días (Carrión-Aguirre, s.f., p. 31).

La siguiente cita cuenta cómo el protagonista al ser víctima de este maltrato tiene baja su autoestima y una idea errónea de su personalidad al considerar que tiene sangre de chinche.

El solitario, cuando camina entre las gentes, es como un leproso. Su lepra, que está hecha de frío y de aislamiento, obliga a que todos se alejen de él. Hiela los ambientes tibios, corta las sonrisas y en su presencia nadie puede ser espontáneo y gracioso. Esto me ha ocurrido desde niño, yo lo sé, como nadie. "Sangre de chinche tiene", decían de mí cuando era pequeño. ¡Sangre de chinche! He ahí lo que me ha pasado; recibí sangre de chinche, sangre de bicho inmundo, en lugar de sangre humana, y fui condenado, con esa sangre, a vivir entre los hombres (Carrión-Aguirre, s.f., p. 24).

Asimismo, vemos un tipo de maltrato emocional en la novela motivo de estudio cuando Darío Nicolás Saralear sintetiza con variados calificativos emocionales a las personas que han formado parte de su vida.

No creo haber hallado alguien puro en mi camino: veo en los ojos de mi pequeño agitarse un nido de víboras: la pobre mujer escuálida que fue mi compañera estaba tan marcada por los dientes de la soledad y el abandono, que la bondad en ella no tenía sitio, sino solamente la envidia, el desasimiento, la nostalgia [...] Mis hermanos, los únicos en quienes he podido leer honduras y oscuridades, ellos, tú lo sabes, Señor, ellos son solamente demonios; no endemoniados, sino demonios; perturban la vida circundante, crean la desdicha, causan dolor, ansiedad, desesperación. En el 
uno predomina el lobo, en el otro la zorra o el cuervo, como quieras; en el fondo, el uno es un devorador de carnes palpitantes; el otro, un devorador de carroña (Carrión-Aguirre, s.f., p. 181).

Otro problema bien marcado en la novela La Espina es la infidelidad protagonizada por Julia Enriqueta que nunca pudo frenar sus instintos sexuales. Poco o nada le importó que, su esposo se encuentre agonizando para perpetrar actos de infidelidad y lujuria. Tampoco le importó cometer estos actos en un hogar donde vivían sus hijos. Como se la describe en la siguiente cita, era una mujer sencilla que no podía diferenciar correctamente lo bueno y lo malo. Lo único que conocía y buscaba era saciar su deseo, aunque sus actos no sean morales.

Yo comprendo cómo se sintió Saralear, al verse sólo, absolutamente solo, sin ayuda posible, tirado al pozo de la soledad. Se derrumbó. No pudo resistir. Esa mujer, la suya, que temblaba a una mirada de él, esa mujer... Sí: toda la miseria: lo arrojó de su lecho, del dormitorio común; le prohibió tocarla; lo confinó en la sala; le negó su cercanía, su piedad. Y le negó, además, su fidelidad: no esperó a que se muriera para echarse amantes (Carrión-Aguirre, s.f., p. 55).

El alcoholismo es un problema social latente y en la novela está muy presente. Ricaurte se convierte en alcohólico, por ello, la siguiente cita refiere la visión que tenía Darío Nicolás Saralear de Ricaurte. Un momento que llena de tensión al personaje principal es cuando su padre decide dar nombre y apellido al hijo que, nunca reconoció. Obviamente, este deseo es desechado por Darío Nicolás Saralear y describe a su padre como un payaso y un borracho.

El viejo sucio, el viejo payaso, había planeado su última inmundicia: cubrirme de vergüenza ante la ciudad entera, reconociéndome como hijo suyo ante un escribano, quitándome el nombre al cual yo había dado fama y prestigio, arrastrando por el cieno la honra de mi madre, quitándome el escudo de hijo legítimo que ella me dejó en su hora de morir... en fin: sometiéndome a la vergüenza, al ludibrio universal, todo para arrancarme luego, en juicio sumario de alimentos, una pensión judicialmente señalada tras investigar mis ingresos. El inmundo payaso, que eso era a tales alturas el viejo boticario borracho, no se daba siquiera cuenta de que me conduciría a la ruina [...] (Carrión-Aguirre, s.f., p. 172).

Otro problema en la novela es la prostitución y la misma se presenta como un momento desagradable para su protagonista Darío Nicolás Saralear. Él se pregunta cómo es posible que las mujeres cometan este acto sin importar las consecuencias. Vemos a continuación dicho acto, cuando sus hermanos lo conducen bajo presión ante una prostituta, él logra ver lo más despreciable a lo que puede caer una persona. 


\section{CIENCIAS SOCIALES}

Le causa odio mirar que en la cama en la que tenía relaciones sexuales esta mujer, duermen sus hijos y son testigos omnipresentes de esos actos repudiables.

Había media luz tras el bastidor. Un espacio de un metro treinta, no más, entre el bastidor y la pared, remotamente blanqueada con cal, piso de ladrillos, estacas en el muro con ropas de mujer, un altar con la Virgen del Cisne, el Corazón de Jesús y dos velitas de a medio, y un camastro, un "estrado" de madera, con su colchón y sábanas nada limpias y una cobija "amarrada”. Al pie, increíblemente, dos niñitos dormidos: los dos hijos de la infeliz ramera muda, dormidos ahí, al pie de la cama donde ella ganaba, para ellos y para el padre, para el rufián, la vida con su pobre cuerpo (Carrión-Aguirre, s.f., pp. 206-207).

Otro problema latente en la novela analizada es la corrupción, un mal endémico que afecta a todos los protagonistas. La política, la democracia y las urnas son el mecanismo que legitiman en el poder a los corruptos. La siguiente cita describe a un hermano corrupto y nos invita a considerar que la política es la actividad favorita de los pícaros corruptos.

Otra vez, oí a Servio Lorenzo, candidato a diputado, decir desde un balcón a una multitud de cretinos, que lo escuchaba con la boca abierta y la razón ausente: "Os juro por mi madre santa, por la mujer inmaculada que me llevó en su vientre, que sabré cumplir con mi deber”. Yo lo oí, y, mientras lo oía mi alma vomitaba. ¡Es indigno mezclar a la propia madre [...] en esas inmundicias! Desde luego, Servio Lorenzo jamás pensaba en cumplir con su deber. Desde luego, también, esos cretinos que lo escuchaban con la boca abierta y que luego votaron por él en estériles urnas, fruto maduro para la cosecha de los pícaros, no sabían cuál sería ese deber (Carrión-Aguirre, s.f., p. 50).

El suicidio es otro ejemplo con del abogado, Darío Nicolás Saralear, cuando se asfixia al tragar la funda de una almohada. Para el protagonista de esta novela, el sufrimiento terrible del abogado fue justificado y propicio para una persona que merecía sufrir por los actos indignos que cometió a lo largo de su vida. Obviamente para Darío Nicolás Saralear el abogado mereció morir de esta forma.

Parece indudable que mi madre estaba invadida de una prisa irresistible porque Saralear se muriese, y que éste, cuyo talento era agudo como aguja, se dio clara cuenta de ello, y un buen día se comió la funda del almohadón del sofá de la sala hasta conseguir que la asfixia lo librara de su miseria [...] Saralear estaba ahí, violáceo, helado, con la funda metida en la boca. Ella, lo sé, me lo contaron mis hermanos, no 
se sorprendió. "Ya era tiempo", parece que dijo, o, por lo menos, lo dio a entender (Carrión-Aguirre, s.f., p. 53).

El abuso sexual es otro problema vigente. Es uno de los actos más reprochables presentes en la humanidad. En la novela La Espina causa estragos leer como dos jóvenes violan a una anciana llamada Luz. La mujer que fue víctima de la violación se sintió destruida y en ese instante tuvo el deseo de morir antes que vivir con la vergüenza de este acto de violencia.

Un miedo mortal la comenzó a invadir cuando sintió tras sí deslizarse a Servio: quiso volverse rápidamente, pues había adivinado algo infinitamente malvado en el rostro de Zoilo, pero fue ya tarde: una mano de hierro se cerró sobre su boca, músculos de hierro también la doblegaron y su pobre humanidad de sesenta y pico de años se vio tendida en los suelos, y sus viejas faldas alzadas, y sus pobres muslos deformados por el reuma y la edad, puestos al aire, miserandos y horribles, y luego, en un instante cuyo horror la llevó más allá de la conciencia, su antigua virginidad se esfumó en medio de brutales golpes y sevicias, a los embates de un feroz macho joven, al cual siguió otro, igualmente feroz y cruel (Carrión-Aguirre, s.f., pp. 153-154).

Otro problema que encontramos en la novela La Espina es el homicidio. Dicho acto repudiable se presenta cuando un joven estaba defecando en un cañabraval. La muerte lo sorprende y es propinada por Servio:

Había estado ahí, haciendo sus necesidades, metido en el vientre del cañabraval, y allí la muerte, una muerte vil y espantosa, una muerte de porquería, lo había sorprendido. El ladrillo que tiró Servio había sido conducido por implacable mano invisible, y se había incrustado casi, brutalmente, en su pobre cabecita llorona. Había caído de espaldas, con los ojos aún llenos de asombro y tristeza. Estaba con los pantalones bajados, muerto, espantosamente muerto sobre sus propios excrementos: moscas impuras lo cubrían, las moscas de los estercoleros, que ahora tenían un banquete de carne. Y para colmo de lo horrible, de lo sucio, de lo infinitamente vil y miserable, un cerdo hozaba entre sus piernas (Carrión-Aguirre, s.f., p. 118).

Finalmente, analizaremos el parricidio, el cual es considerado uno de los actos más violentos observados por la humanidad. En la novela La espina el parricidio no llega a concretarse, sin embargo, llega a ser considerado como una opción a ser cometida, debido a que, Darío Nicolás Saralear, se enfurece cuando se entera que su padre biológico lo desea registrar con su apellido ante las autoridades pertinentes.

El protagonista prefiere matar a su padre antes que cambiar su apellido que le había dado reconocimiento, prestigio y posesiones económicas en su sociedad. Se pregunta 
cómo un hombre como su padre, que nunca se compadeció, quiera reconocer a su único hijo. A continuación, consignamos la siguiente cita que evidencia lo mencionado:

Jamás tuve tanta ira, jamás también corrí un riesgo tan grande, nunca me vi ante un abismo más lleno de cieno y, desde luego, nunca, nunca, tuve tanto miedo. Resolví ir donde el malvado payaso y hacerlo abandonar su inmundo propósito, firmemente resuelto a ir hasta el asesinato, el parricidio, claro está, pues eso resultaría a la postre, para defenderme de tan espantoso y sucio peligro (Carrión-Aguirre, s.f., p. 172).

Vemos que el sufrimiento, maltrato y violencia intrafamiliar que vivió el protagonista de la novela La espina, Darío Nicolás Saralear, se vuelve un hecho normal y recurrente, haciéndonos pensar que, no hay otra alternativa para dichas vejaciones.

\section{Conclusiones}

Se puede concluir que en la novela La Espina se puede determinar que el ambiente social y cultural en que se desarrolla la historia está lleno de conflictos y problemas, uno de ellos, el maltrato y la violencia intrafamiliar que sufren sus protagonistas.

Esta novela narra de forma cruda y desmedida la vida de Darío Nicolás Saralear. Su infancia fue marcada de forma infeliz y cruel dentro de un ambiente de soledad y desgracia. Se relata el ambiente y la naturaleza palpable de cada uno de los personajes.

El protagonista de la novela La espina Darío Nicolás Saralear llegó a sus años de madurez rodeado de riqueza y soledad. Trató de ser una persona resiliente; pero, lamentablemente no pudo superarse de forma real y verdadera. No pudo amar ni perdonar a las personas que le hicieron mucho daño desde muy niño y que marcaron su vida de forma dolorosa y solitaria.

\section{Lista de referencias}

Carrión Aguirre, A. (s.f.). La espina. Guayaquil-Quito: Ariel.

Sarango, C. (2020). La dignidad humana en Curipamba de Ángel Felicísimo Rojas. Encuentros. Revista de Ciencias Humanas, Teoría Social y Pensamiento Crítico., (11), 93-100.

Vargas Llosa, M. (1990). La verdad de las mentiras. Alfaguara. 